\title{
PARP-1-Targeted Auger Emitters Display High-LET Cytotoxic Properties In Vitro but Show Limited Therapeutic Utility in Solid Tumor Models of Human Neuroblastoma
}

\author{
Hwan Lee ${ }^{1}$, Aladdin Riad ${ }^{1}$, Paul Martorano ${ }^{1}$, Adam Mansfield ${ }^{1}$, Minu Samanta ${ }^{2}$, Vandana Batra ${ }^{2}$, Robert H. Mach ${ }^{1}$, \\ John M. Maris ${ }^{2}$, Daniel A. Pryma ${ }^{1}$, and Mehran Makvandi ${ }^{1}$ \\ ${ }^{I}$ Department of Radiology, University of Pennsylvania Perelman School of Medicine, Philadelphia, Pennsylvania; and ${ }^{2}$ Division of \\ Oncology and Center for Childhood Cancer Research, Children's Hospital of Philadelphia, Philadelphia, Pennsylvania
}

\begin{abstract}
The currently available therapeutic radiopharmaceutical for highrisk neuroblastoma, ${ }^{131}$ I-metaiodobenzylguanidine, is ineffective at targeting micrometastases because of the low-linear-energy-transfer (LET) properties of high-energy $\beta$-particles. In contrast, Auger radiation has high-LET properties with nanometer ranges in tissue, efficiently causing DNA damage when emitted near DNA. The aim of this study was to evaluate the cytotoxicity of targeted Auger therapy in preclinical models of high-risk neuroblastoma. Methods: We used a radiolabled poly(adenosine diphosphate ribose) polymerase (PARP) inhibitor called ${ }^{125}$ I-KX1 to deliver Auger radiation to PARP1 , a chromatin-binding enzyme overexpressed in neuroblastoma. The in vitro cytotoxicity of ${ }^{125} \mathrm{I}-\mathrm{KX} 1$ was assessed in 19 neuroblastoma cell lines, followed by in-depth pharmacologic analysis in a sensitive and resistant pair of cell lines. Immunofluorescence microscopy was used to characterize ${ }^{125} \mid-K X 1$-induced DNA damage. Finally, in vitro and in vivo microdosimetry was modeled from experimentally derived pharmacologic variables. Results: ${ }^{125} \mathrm{I}-\mathrm{KX} 1$ was highly cytotoxic in vitro across a panel of neuroblastoma cell lines, directly causing double-strand DNA breaks. On the basis of subcellular dosimetry, ${ }^{125} \mathrm{I}-\mathrm{KX} 1$ was approximately twice as effective as ${ }^{131} \mid-K X 1$, whereas cytoplasmic ${ }^{125} \mid$-metaiodobenzylguanidine demonstrated low biological effectiveness. Despite the ability to deliver a focused radiation dose to the cell nuclei, ${ }^{125} \mathrm{I}-\mathrm{KX} 1$ remained less effective than its a-emitting analog ${ }^{211} \mathrm{At}-\mathrm{MM} 4$ and required significantly higher activity for equivalent in vivo efficacy based on tumor microdosimetry. Conclusion: Chromatin-targeted Auger therapy is lethal to high-risk neuroblastoma cells and has the potential to be used in micrometastatic disease. This study provides the first evidence for cellular lethality from a PARP-1-targeted Auger emitter, calling for further investigation into targeted Auger therapy.
\end{abstract}

Key Words: radiopharmaceutical therapy; Auger emitter; PARP-1; high-risk neuroblastoma

J Nucl Med 2020; 61:850-856

DOI: 10.2967/jnumed.119.233965

Received Jul. 16, 2019; revision accepted Oct. 9, 2019.

For correspondence or reprints contact: Mehran Makvandi, University of Pennsylvania Perelman School of Medicine, Donner D001031, HUP, 3400 Spruce St., Philadelphia, PA 19104.

E-mail: makvandi@pennmedicine.upenn.edu

Published online Nov. 1, 2019.

COPYRIGHT (C 2020 by the Society of Nuclear Medicine and Molecular Imaging.
$\mathbf{N}$ euroblastoma is the most common extracranial solid tumor in childhood, with only up to a 50\% 5-y survival rate in high-risk patients (1). Relapsed cases are often managed with ${ }^{131}$ I-metaiodobenzylguanidine $\left({ }^{131} \mathrm{I}-\mathrm{MIBG}\right)$ radiopharmaceutical therapy, but its suboptimal therapeutic efficacy and very low complete response rate remain unsatisfactory (2). The main limitation of ${ }^{131} \mathrm{I}-\mathrm{MIBG}$ therapy is the low linear energy transfer (LET) of $\beta$-particles, which are unable to produce sufficient radiation fields for lethal DNA damage in micrometastatic disease (3).

Our group has recently developed a ${ }^{211} \mathrm{At}$-labeled radiopharmaceutical, ${ }^{211}$ At-MM4, which has shown strong antitumor efficacy in neuroblastoma (4). In contrast to MIBG, which targets the norepinephrine transporter, ${ }^{211}$ At-MM4 binds to poly(adenosine diphosphate ribose) polymerase 1 (PARP-1), a chromatin-associated protein overexpressed in neuroblastoma (4).

PARP-targeted radiopharmaceutical therapeutics not only enable efficient delivery of radiation to DNA but also allow using other types of high-LET therapeutic radiation that otherwise would not penetrate cells. Auger electrons are emitted in cascades and have a low energy of up to $100 \mathrm{keV}$ with less than a $0.5-\mu \mathrm{m}$ range (5). The most extensively investigated Auger emitter is ${ }^{125} \mathrm{I}$, with a 60 -d half-life and 20-25 Auger emissions per decay (5), exhibiting high relative biological effectiveness (RBE) and a low oxygen-enhancement ratio characteristic of high-LET radiation when integrated into DNA (6).

Therefore, targeting PARP-1 with an Auger-emitting ${ }^{125}$ I-labeled small molecule is an attractive strategy to deliver high-LET radiation to neuroblastoma. One such radiopharmaceutical is ${ }^{125} \mathrm{I}-\mathrm{KX} 1$, an analog of ${ }^{211}$ At-MM4 in which ${ }^{211}$ At is replaced by ${ }^{125} \mathrm{I}(4,7)$. Although ${ }^{125} \mathrm{I}-\mathrm{KX} 1$ has previously been described as a biomarker to quantify PARP-1 expression in ovarian cancer models (7), its therapeutic use has not been investigated in any cancer models.

In the present study, we used ${ }^{125} \mathrm{I}-\mathrm{KX} 1$ to examine the therapeutic potential of a PARP-1-targeted Auger emitter in preclinical models of high-risk neuroblastoma (Fig. 1). After characterizing its PARPdependent in vitro cytotoxicity, we made a dosimetry-based comparison of ${ }^{125} \mathrm{I}-\mathrm{KX} 1$ to $\alpha-, \beta-, \gamma-$, and cytoplasmic Auger radiation to evaluate its effectiveness relative to other conventional and experimental therapies. Finally, a comparison with its $\alpha$-emitting analog ${ }^{211}$ At-MM4 was made using in vivo tumor dosimetry to explore the feasibility of using Auger-emitting PARP-targeted radiopharmaceutical therapeutics for in vivo therapy.

\section{MATERIALS AND METHODS}

The overall experimental design is shown in Figure 1. 


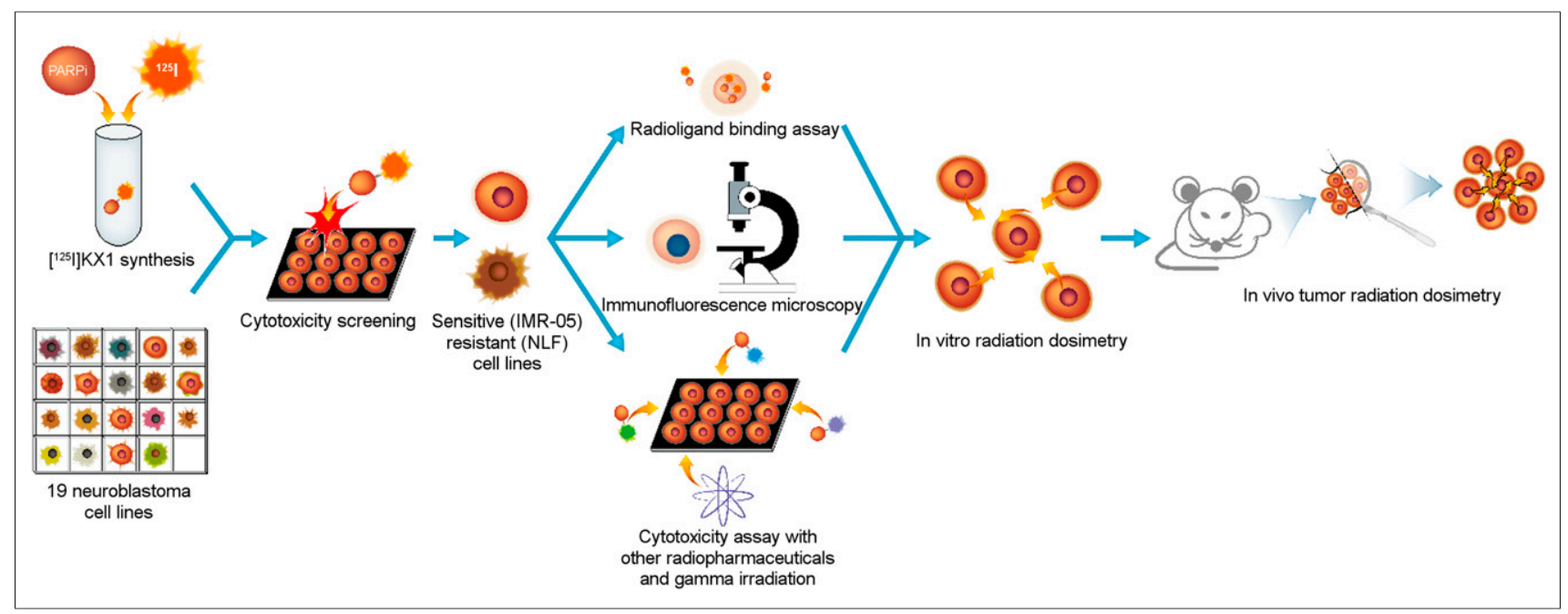

FIGURE 1. Workflow for preclinical evaluation of ${ }^{125} \mathrm{I}-\mathrm{KX} 1$ in high-risk neuroblastoma. Nineteen human neuroblastoma cell lines were screened for cytotoxic sensitivity to ${ }^{125} \mathrm{I}-\mathrm{KX} 1$. IMR-05 and NLF were chosen as representative cell lines for downstream experiments. Radioligand binding assay, immunofluorescence microscopy, and further cytotoxicity screening were followed by in vitro and in vivo radiation dosimetry.

\section{Chemistry and Radiochemistry}

Nonradioactive KX1, ${ }^{125} \mathrm{I}-\mathrm{KX} 1,{ }^{211} \mathrm{At}-\mathrm{MM} 4$, and ${ }^{125} \mathrm{I}-\mathrm{MIBG}$ were synthesized as previously described, with greater than $95 \%$ chemical and radiochemical purity $(4,7,8) .{ }^{131} \mathrm{I}-\mathrm{KX} 1$ was synthesized in an identical manner to ${ }^{125} \mathrm{I}-\mathrm{KX} 1$. The specific activities of ${ }^{125} \mathrm{I}-\mathrm{KX} 1 /{ }^{125} \mathrm{I}-\mathrm{MIBG}$, ${ }^{131} \mathrm{I}-\mathrm{KX} 1$, and ${ }^{211} \mathrm{At}-\mathrm{MM} 4$ were 81.4 , 592, and $16.021 \mathrm{GBq} / \mu \mathrm{mol}$, respectively.

\section{Cell Culture}

Nineteen human neuroblastoma cell lines were obtained from the Children's Hospital of Philadelphia Cell Bank (Supplemental Table 1; supplemental materials are available at http://jnm.snmjournals.org) and were cultured as previously described (4).

\section{Immunofluorescence Microscopy}

To characterize the specificity of ${ }^{125} \mathrm{I}-\mathrm{KX} 1$ Auger-induced DNA damage, IMR-05 and NLF cells were treated with a $1.85 \mathrm{MBq} / \mathrm{mL}$ concentration of ${ }^{125} \mathrm{I}-\mathrm{KX} 1$ with or without $500 \mathrm{nM}$ veliparib for $1 \mathrm{~h}$ and were subsequently analyzed by assessing $\gamma \mathrm{H} 2 \mathrm{AX}$ (05-636; Millipore) and PARP-1 (46D11; Cell Signaling Technology) fluorescence under manufacturer-recommended conditions. Secondary antibodies were used at a 1:200 dilution (A32723 and A32794; Invitrogen). The slides were mounted using Prolong Glass with NucBlue stain (P36985; Invitrogen), and images were acquired at $\times 40$ magnification on a Leica STED 3X super-resolution confocal microscope. $\gamma \mathrm{H} 2 \mathrm{AX}$ fluorescence was quantified on mapped nuclei by intensity and normalized to nucleus area using the Speckle Counting pipeline of the CellProfiler software (9). Three random fields of view were quantified per treatment condition.

\section{In Vitro Cytotoxicity}

The cytotoxicity of ${ }^{125} \mathrm{I}-\mathrm{KX} 1$ was screened in 19 human neuroblastoma cell lines as previously described (4), with 72-h treatments of $0.925 \mathrm{~Bq} / \mathrm{mL}$ to $925 \mathrm{kBq} / \mathrm{mL}$ concentrations of ${ }^{125} \mathrm{I}-\mathrm{KX} 1$ compared with $100 \mathrm{pM}$ to $100 \mu \mathrm{M}$ KX1 as nonradioactive controls. Half-maximal effective concentrations $\left(\mathrm{EC}_{50}\right)$ of ${ }^{125} \mathrm{I}-\mathrm{KX} 1$ were correlated with $\mathrm{EC}_{50}$ values of KX1 and published $\mathrm{EC}_{50}$ values of ${ }^{211} \mathrm{At}-\mathrm{MM} 4$ (4), as well as with PARP-1 messenger RNA (mRNA) expression levels measured by reverse transcription polymerase chain reaction.

For all downstream experiments, IMR-05 and NLF were chosen as examples of a sensitive and a resistant cell line, respectively (Fig. 1). External $\gamma$-radiation was delivered with a ${ }^{137} \mathrm{Cs}$ source at a dose rate of $1.5 \mathrm{cGy} / \mathrm{s}$, up to a 2-Gy total dose for IMR-05 and 6 Gy for NLF. The cells were seeded immediately after the irradiation, and survival fraction was quantified after $72 \mathrm{~h}$ as in the ${ }^{125} \mathrm{I}-\mathrm{KX} 1$ cytotoxicity assay. Survival fraction was plotted against radiation dose using the linear-quadratic model (10).

As a model for targeted low-LET $\beta$-therapy, a cytotoxicity assay with ${ }^{131} \mathrm{I}-\mathrm{KX} 1$ was performed on IMR-05 and NLF cell lines with a dose range of $2.4 \mathrm{kBq} / \mathrm{mL}$ to $37 \mathrm{MBq} / \mathrm{mL}$. Cytotoxicity data for ${ }^{211} \mathrm{At}-\mathrm{MM} 4$ and unconjugated free ${ }^{211} \mathrm{At}\left({ }^{211} \mathrm{At}-\mathrm{NaAt}^{\mathrm{x}}\right)$ were obtained from the literature as examples of targeted and nontargeted $\alpha$-particle therapy, respectively (4). Finally, a cytotoxicity assay with ${ }^{125} \mathrm{I}-\mathrm{MIBG}$ was performed at a dose range of $0.925 \mathrm{~Bq} / \mathrm{mL}$ to $925 \mathrm{kBq} / \mathrm{mL}$ to model cytoplasmic Auger emitter therapy. ${ }^{125} \mathrm{I}-\mathrm{MIBG}$ served as a strict negative radioactive control in lieu of free ${ }^{125} \mathrm{I}$, which is not taken up by neuroblastoma cells and therefore deposits only an extracellular Auger dose (11). Experiments were completed in triplicates 3 independent times.

\section{Radiopharmacology}

A radioligand saturation binding assay was performed with ${ }^{125} \mathrm{I}-$ KX1 on IMR-05 and NLF cell lines as previously published (4). The maximum number of binding sites $\left(B_{\max }\right)$ was expressed as targets per cell by normalizing to the cell number using a Countess II Automated Cell Counter (Thermo Fisher Scientific). The binding affinity $\left(\mathrm{K}_{\mathrm{d}}\right)$ of ${ }^{211}$ At-MM4 was obtained indirectly by comparison to ${ }^{125} \mathrm{I}-\mathrm{KX} 1$ binding under nonsaturating concentrations up to $37 \mathrm{kBq} / \mathrm{mL}$ (Supplemental Eq. 1). ${ }^{125} \mathrm{I}-\mathrm{MIBG}$ uptake was measured after a 2-h incubation at the nonsaturating concentrations used in the cytotoxicity assay $(\leq 925 \mathrm{kBq} / \mathrm{mL})$ with or without blocking with $10 \mu \mathrm{M}$ of desipramine (12).

\section{Subcellular Radiation Dosimetry}

To calculate the radiation dose to the cell nucleus from ${ }^{125} \mathrm{I}-\mathrm{KX} 1$, ${ }^{131} \mathrm{I}-\mathrm{KX} 1,{ }^{125} \mathrm{I}-\mathrm{MIBG}$, and ${ }^{211} \mathrm{At}-\mathrm{MM} 4$, on-target cumulated activity was derived from the radiopharmacology data (Supplemental Eq. 2). Then, the radiation dose to the cell nucleus was obtained using Monte Carlo simulation with Medical Internal Radiation Dosimetry Cell (MIRDcell), version 2.1, as described previously (13). The radii of the cell and its nucleus were measured with phase-contrast and fluorescence microscopy with 4',6-diamidino-2-phenylindole, respectively.

To calculate the cross-dose from neighboring cells, the growth rates of IMR-05 and NLF cell lines were measured by counting the cells daily with a Countess II Automated Cell Counter. Then, the cell 
numbers, cumulated activity, radionuclide information, and dimensions of the wells in the cytotoxicity assay were applied to the 2dimensional dosimetry model on MIRDcell to obtain cross-dose values. For nonspecific $\alpha$-therapy with ${ }^{211} \mathrm{At}-\mathrm{NaAt}^{\mathrm{x}}$, the radiation dose to the culture medium at the bottom of the wells was used to represent cellular radiation dose.

With the dosimetric calculations, the cytotoxic dose-response curves for the radiopharmaceuticals were transformed to radiation doseresponse curves based on the linear-quadratic model. Using $50 \%$ survival as the reference endpoint, the RBE among the different types of radiation was calculated.

\section{In Vivo Tumor Dosimetry with 3-Dimensional Modeling}

To compare the therapeutic efficacy of ${ }^{125} \mathrm{I}-\mathrm{KX} 1$ and ${ }^{211} \mathrm{At}-\mathrm{MM} 4$ for in vivo therapy, radiation dosimetry was performed with densely packed 3-dimensional face-centered cubic modeling of a solid xenograft tumor consisting of spheric IMR-05 tumor cells. Radiation dosimetry was then performed both macroscopically and microscopically. First, per decay event in every tumor cell, the radiation dose to the macroscopic tumor volume due to the entire particulate energy absorption was calculated. In addition, the subcellular radiation dose to the tumor cell nuclei was calculated by accounting for the self- and crossdose contributions based on the geometric distances among tumor cells in the 3-dimensional model. The $\mathrm{S}$ value for cross-dose calculation was obtained for each cell-cell pair on MIRDcell, version 2.1 (13).

Finally, the nuclear radiation dose per decay event was adjusted by differences in RBE and $\mathrm{K}_{\mathrm{d}}$ to PARP-1, as well as effective half-lives for ${ }^{125} \mathrm{I}-\mathrm{KX} 1$ and ${ }^{211} \mathrm{At}-\mathrm{MM} 4$ from previously published in vivo biodistribution data (4,7). The adjusted dosimetry results enabled comparison of equivalent therapeutic administered doses between ${ }^{125} \mathrm{I}-\mathrm{KX} 1$ and ${ }^{211}$ At-MM4.

\section{Statistical Analysis}

The $\log \left(\mathrm{EC}_{50}\right)$ values between ${ }^{125} \mathrm{I}-\mathrm{KX} 1$ and $\mathrm{KX} 1$ for each cell line were compared using an unpaired $t$ test. Linear regression was performed to determine the variation in $\log \left(\mathrm{EC}_{50}\right)$ of ${ }^{125} \mathrm{I}-\mathrm{KX} 1$ with respect to $\log \left(\mathrm{EC}_{50}\right)$ of $\mathrm{KX} 1$ and ${ }^{211} \mathrm{At}-\mathrm{MM} 4$, as well as with respect to PARP-1 mRNA level. The $\gamma \mathrm{H} 2 \mathrm{AX}$ fluorescence intensity of the cells treated with ${ }^{125} \mathrm{I}-\mathrm{KX} 1$ was compared with those of other treatment conditions using an unpaired $t$ test. The $\mathrm{B}_{\max }, \mathrm{K}_{\mathrm{d}}$, growth rate, $\log \left(\mathrm{EC}_{50}\right)$, and dose for $50 \%$ cell survival were compared between IMR-05 and NLF cell lines using an unpaired $t$ test. All statistical comparisons were 2-tailed, and a $P$ value of less than 0.05 was considered statistically significant. Prism (version 7; GraphPad Software) was used to perform all statistical tests and data fitting. Numeric values are reported as mean \pm SE of measurement (SEM).

\section{RESULTS}

\section{Immunofluorescence Microscopy}

In IMR-05 and NLF cells, treatment with ${ }^{125} \mathrm{I}-\mathrm{KX} 1$ caused double-strand DNA breaks as visualized with $\gamma \mathrm{H} 2 \mathrm{AX}$ on immunofluorescence microscopy (Fig. 2). $\gamma \mathrm{H} 2 \mathrm{AX}$ was substantially reduced when ${ }^{125} \mathrm{I}-\mathrm{KX} 1$ binding to PARP-1 was blocked by $500 \mathrm{nM}$ of veliparib.

\section{In Vitro Cytotoxicity of ${ }^{\mathbf{1 2 5}} \mathrm{I}-\mathrm{KX} \mathbf{1}$}

Compared with the nonradioactive analog $\mathrm{KX} 1,{ }^{125} \mathrm{I}-\mathrm{KX} 1 \mathrm{dem}-$ onstrated $10^{4}-10^{6}$ times greater cytotoxicity than $\mathrm{KX} 1$ on a molar scale (Figs. 3A $[P<0.0001]$ and 3B). Sensitivity to ${ }^{125} \mathrm{I}-\mathrm{KX} 1$ and $\mathrm{KX} 1$ was moderately correlated $\left(R^{2}=0.58, P<0.001\right.$, for nonzero slope), with an exponential increase in sensitivity to ${ }^{125} \mathrm{I}-\mathrm{KX} 1$ (slope, $2.15 \pm 0.47$ on log-log plot) (Fig. 3C). Sensitivity to ${ }^{125} \mathrm{I}-$ KX1 and ${ }^{211}$ At-MM4 showed a strong positive correlation $\left(R^{2}=\right.$ $0.93, P<0.0001$, for nonzero slope) with a 1 -to-1 relationship (slope,

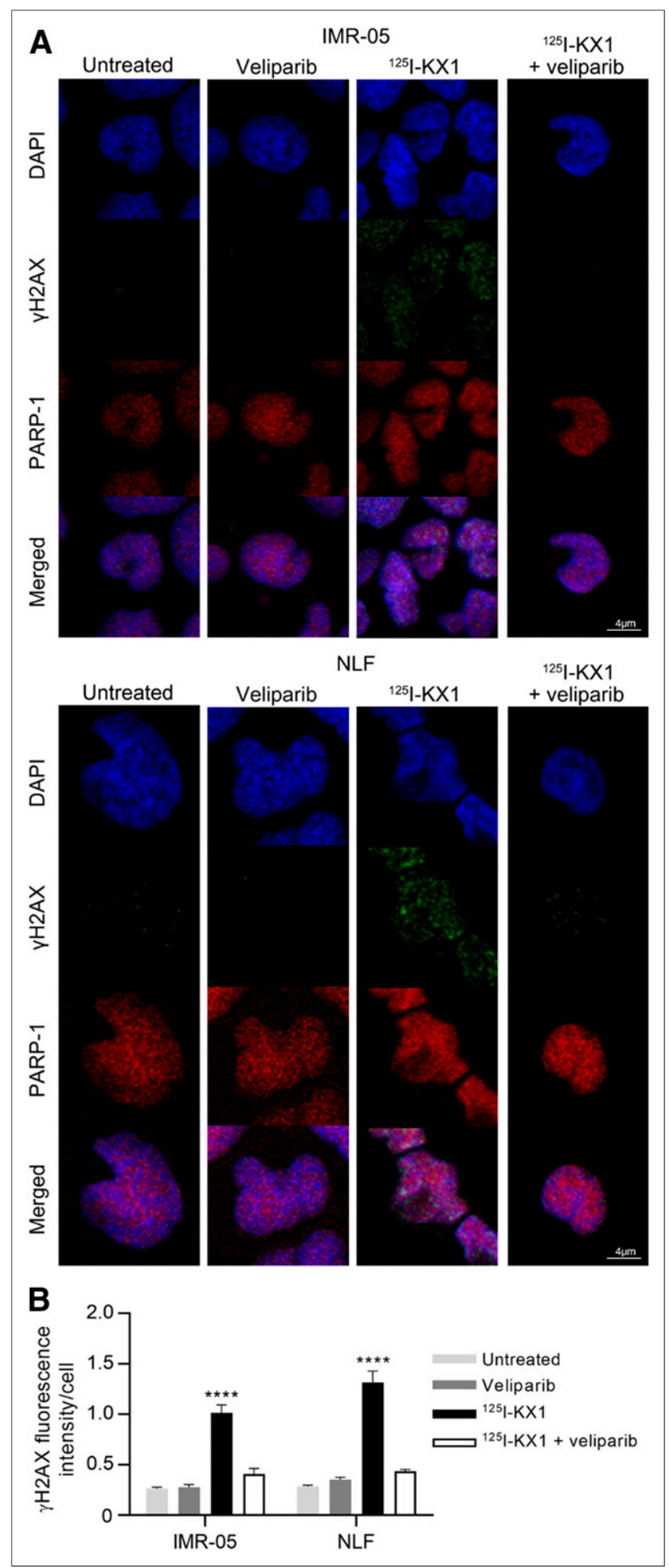

FIGURE 2. Dependency of ${ }^{125 \mid-K X 1-i n d u c e d ~ D N A ~ d a m a g e ~ o n ~ P A R P-1 . ~(A) ~}$ Immunofluorescence microscopy images with $\mathrm{YH} 2 \mathrm{AX}$ show ${ }^{125}$-KX1-induced double-strand DNA breaks, which were substantially blocked with veliparib. (B) Quantification of fluorescence intensity revealed statistically significant yH2AX signal increase with ${ }^{125} \mathrm{I}-\mathrm{KX} 1$ relative to other conditions. ${ }^{\star \star \star \star} P<0.0001$.

$1.07 \pm 0.08$ ) (Fig. 3D). PARP-1 mRNA level was only minimally correlated with sensitivity to ${ }^{125} \mathrm{I}-\mathrm{KX} 1\left(R^{2}=0.23, P<0.05\right.$, for nonzero slope) (Fig. 3E). 

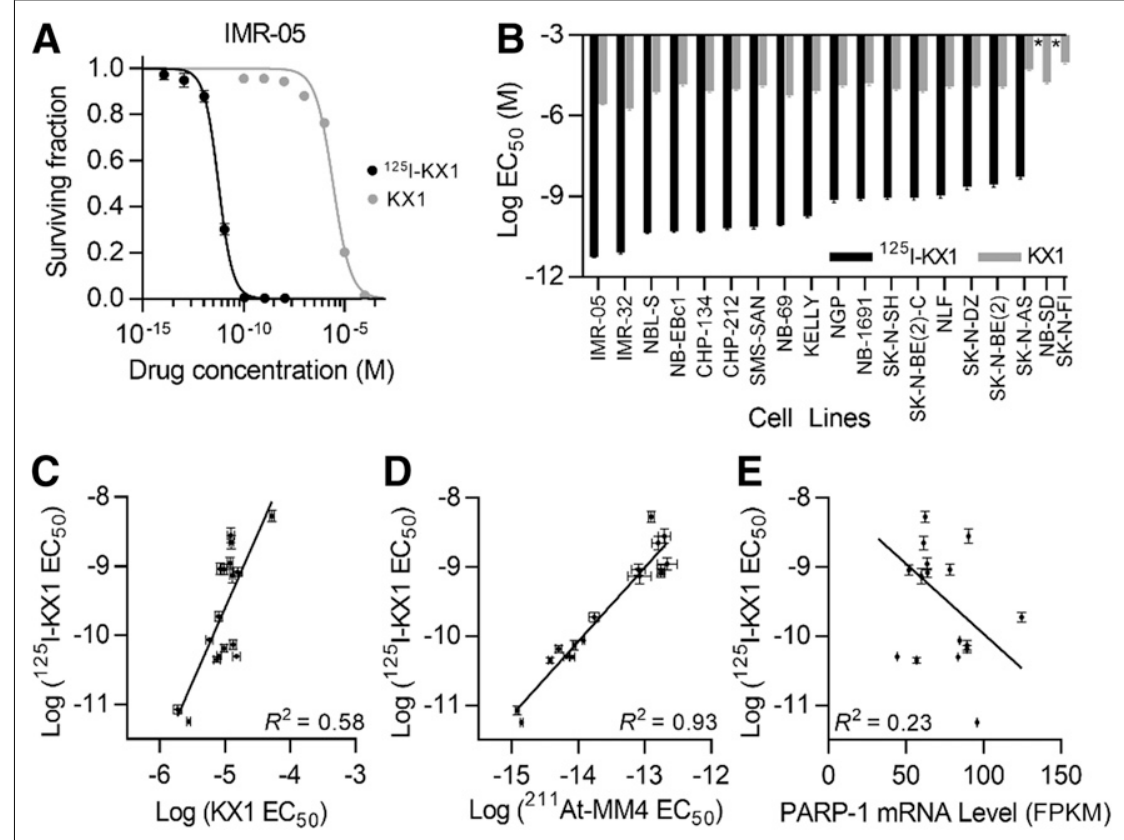

FIGURE 3. In vitro studies evaluating ${ }^{125} \mid-K X 1$-induced cytotoxicity in neuroblastoma cell lines. (A) Representative cytotoxic dose-response curves for ${ }^{125} \mid-K X 1$ and nonradioactive $K X 1$ in neuroblastoma cell line (IMR-05). (B) Waterfall plot of $E_{50}$ values for ${ }^{125}{ }^{2}-K X 1$ and $K X 1$ in panel of 19 neuroblastoma cell lines. ${ }^{*}$ Less than $50 \%$ cell kill in dose range tested $\left(P<0.0001\right.$ for ${ }^{125}$ I-KX1 vs. KX1 in all 17 cell lines with $>50 \%$ cytotoxicity). (C-E) Sensitivity to ${ }^{125}-\mathrm{KX} 1$ was correlated with sensitivity to $\mathrm{KX} 1$ (C) and ${ }^{211} \mathrm{At}-\mathrm{MM} 4(\mathrm{D})$, but minimally with PARP-1 mRNA level (E). FPKM = fragments per kilobase million.

Although IMR-05 cells were more sensitive to all forms of radionuclide therapy than NLF $(P<0.0001)$, different radiopharmaceuticals maintained the same order of potency relative to one another in both cell lines (Fig. 4A). The most potent radiopharmaceutical was ${ }^{211}$ At-MM4, followed by ${ }^{125} \mathrm{I}-\mathrm{KX} 1,{ }^{211} \mathrm{At}-\mathrm{NaAt}{ }^{\mathrm{x}},{ }^{131} \mathrm{I}-\mathrm{KX} 1$, and ${ }^{125} \mathrm{I}-$ MIBG (Supplemental Table 2). As with radiopharmaceuticals, external $\gamma$-irradiation was more lethal, with a lower $\mathrm{D}_{50}$ in IMR-05 $(0.71 \pm$ $0.02 \mathrm{~Gy})$ than in NLF $(3.7 \pm 0.1 \mathrm{~Gy})(P<0.0001)$ (Fig. 4B).

\section{Radiopharmacology}

Radioligand binding assays revealed that IMR-05 had higher ${ }^{125}$ I-KX1 uptake $(P<0.0001)$ but lower ${ }^{125}$ I-MIBG uptake $(P<$ $0.0001)$ than NLF, whereas the $\mathrm{K}_{\mathrm{d}}$ of ${ }^{125} \mathrm{I}-\mathrm{KX} 1(P=0.40)$ and ${ }^{211}$ At-MM4 $(P=0.38)$ was similar between the 2 cell lines (Supplemental Figs. 1A-1C), suggesting different expression levels of structurally identical target proteins. IMR-05 demonstrated a higher growth rate than NLF $(P<0.0001)$ (Supplemental Fig. 1D), leading to a higher cross-dose deposition due to proximity between adjacent cells. On microscopy, the nuclear and cellular radii of IMR-05 cells were measured to the nearest whole number at 6 and $8 \mu \mathrm{m}$, respectively, compared with NLF with 9- and 12- $\mu \mathrm{m}$ radii (Supplemental Fig. 1E).

\section{Subcellular Radiation Dosimetry}

Despite the wide variation in $\mathrm{EC}_{50}$, dosimetric analysis revealed that the RBEs of the radiopharmaceuticals were within the same order of magnitude. Without PARP-1 targeting, $\alpha$-particles from ${ }^{211} \mathrm{At}^{-N a A t}{ }^{\mathrm{x}}$ demonstrated 3.6-3.7 times greater RBE than $\gamma$-irradiation (Fig. 4B). On the other hand, cytoplasmic Auger radiation from ${ }^{125}$ I-MIBG was slightly weaker than $\gamma$-radiation in IMR-05 (RBE, 0.65) and equally efficacious in NLF (RBE, 1.0).
Among the PARP-1-targeted radiopharmaceuticals, the $\alpha$-emitting ${ }^{211}$ At-MM4 remained the most effective, with RBEs of 6.3-6.7, compared with the high-energy $\beta$-emitting ${ }^{131} \mathrm{I}-\mathrm{KX} 1$ (Fig. 4C). In contrast to ${ }^{125} \mathrm{I}-\mathrm{MIBG}$, the Auger-emitting ${ }^{125} \mathrm{I}-\mathrm{KX} 1$ was more effective than ${ }^{131} \mathrm{I}-\mathrm{KX} 1$, with RBEs of 1.8-1.9. As expected from their high LET or low dose rate, all the targeted radiopharmaceuticals demonstrated linear ( $\alpha$-dominant) survival curves in the linearquadratic model (Supplemental Table 3) (10). Therefore, the RBEs were maintained across a different choice of endpoints. A summary of the in vitro dosimetry results and RBEs is provided in Table 1.

\section{In Vivo Tumor Dosimetry with 3-Dimensional Modeling}

The face-centered cubic tumor model and target volumes are represented in Figures $5 \mathrm{~A}$ and $5 \mathrm{~B}$, respectively. When the radiation dose to the entire tumor volume was considered, ${ }^{211}$ At-MM4 deposited 350 times more dose to the tumor per decay event than did ${ }^{125} \mathrm{I}-\mathrm{KX} 1$ because of the much higher energy carried by the $\alpha$-particles than by Auger electrons. Compared with the entire tumor dose, the radiation dose only to the tumor cell nuclei was higher with ${ }^{125} \mathrm{I}-\mathrm{KX} 1$ because of its highly localized dose deposition centered on the nuclei, whereas it was unchanged with ${ }^{211}$ AtMM4 (Fig. 5C). Therefore, compared with ${ }^{125} \mathrm{I}-\mathrm{KX} 1,{ }^{211} \mathrm{At}-\mathrm{MM} 4$ deposited only a 150 times higher tumor-nucleus dose per decay event.

Previously published in vivo biodistribution results for ${ }^{211}$ AtMM4 and ${ }^{125} \mathrm{I}-\mathrm{KX} 1$ have been remarkably similar because of their identical chemical structures except for the radionuclide $(4,7)$. Although the effective half-life of ${ }^{125} \mathrm{I}-\mathrm{KX} 1(1.5 \mathrm{~h})$ is approximately $36 \%$ longer than that of ${ }^{211}$ At-MM4 $(1.1 \mathrm{~h})$ because of the longer physical half-life of ${ }^{125} \mathrm{I}$, it has approximately $35 \%$ less target $\mathrm{K}_{\mathrm{d}}(5.8 \mathrm{nM})$ than ${ }^{211} \mathrm{At}-\mathrm{MM} 4(4.3 \mathrm{nM})$ in the IMR-05 cell line. Given the small differences in biologic distribution between the 2 compounds, the primary difference between ${ }^{211} \mathrm{At}-\mathrm{MM} 4$ and ${ }^{125} \mathrm{I}-\mathrm{KX} 1$ for in vivo efficacy estimation lies in the RBE of 3.5. Taking into account the 3.5-fold higher RBE and the 150-fold greater nuclear radiation dose per decay-both being in favor of ${ }^{211}$ At-MM4 - administration of a 530-fold greater activity of ${ }^{125} \mathrm{I}$ $\mathrm{KX} 1$ is required for in vivo efficacy equivalent to ${ }^{211} \mathrm{At}-\mathrm{MM} 4$.

\section{DISCUSSION}

The present study evaluated the feasibility of chromatin-targeted high-LET Auger electron therapy in high-risk neuroblastoma with the iodinated PARP-1 inhibitor ${ }^{125} \mathrm{I}-\mathrm{KX} 1$. We first validated the basic mechanism of ${ }^{125} \mathrm{I}-\mathrm{KX} 1$-induced cytotoxicity: ${ }^{125} \mathrm{I}-\mathrm{KX} 1$ causes double-strand DNA breaks dependent on binding to active PARP-1 (Fig. 2) and not associated with pharmacologic inhibition (Figs. 3A and 3B).

Since sensitivity to PARP inhibitors such as KX1 is strongly correlated with the number of pharmacologically active binding 

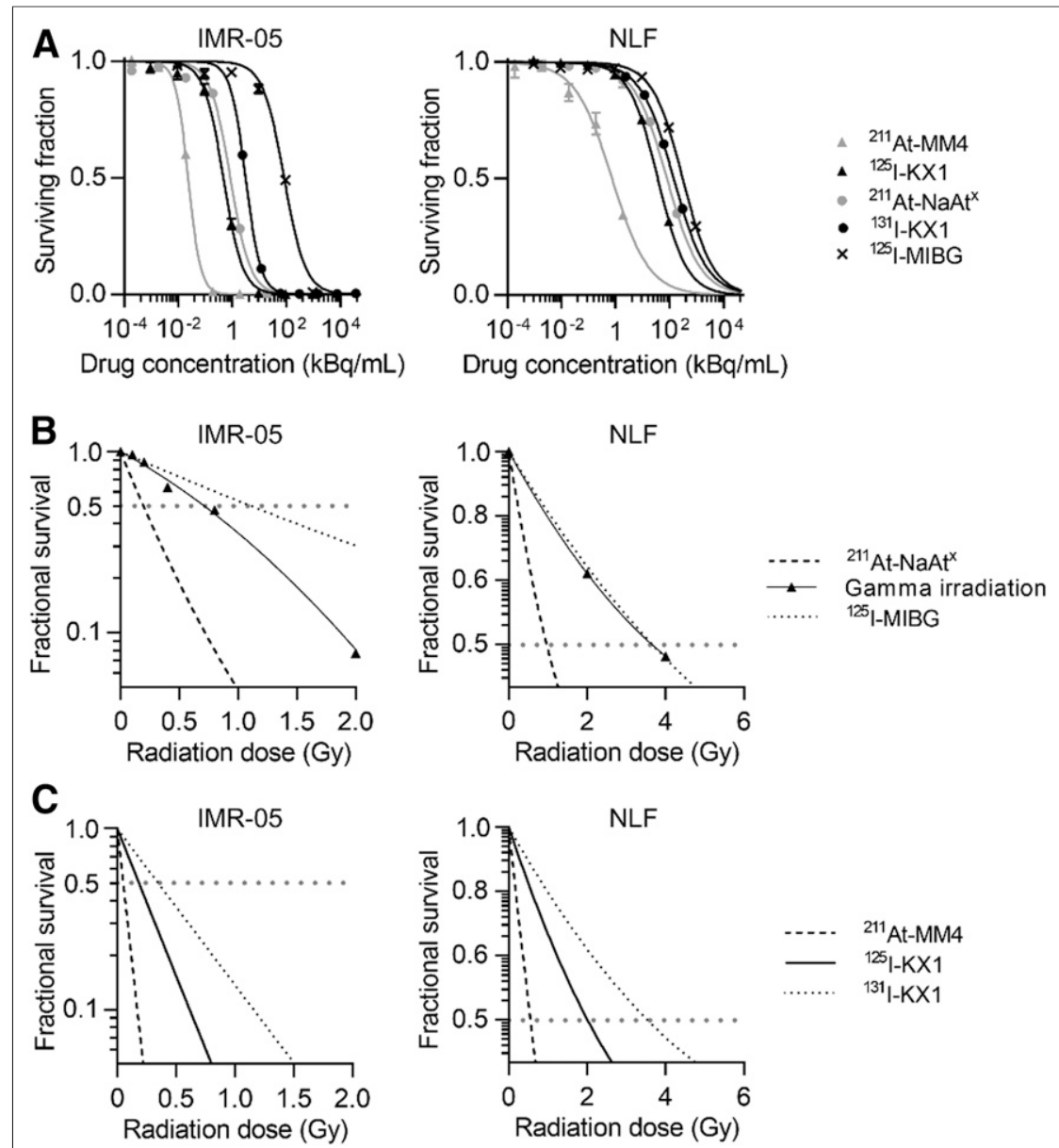

FIGURE 4. Response to various types of radiotherapy with radiation dosimetry. (A) Cytotoxic dose-response curves for ${ }^{211} \mathrm{At}-\mathrm{MM} 4,{ }^{125} \mathrm{I}-\mathrm{KX} 1,{ }^{211} \mathrm{At}-\mathrm{NaAt}$, ${ }^{131} \mathrm{I}-\mathrm{KX} 1$, and ${ }^{125} \mathrm{I}-\mathrm{MIBG}$ based on radioactivity concentration. (B) Cell survival curves for nontargeted radiotherapy with external $y$ irradiation, ${ }^{211} \mathrm{At}-\mathrm{NaAt}^{\mathrm{x}}$, and ${ }^{125}$ |-MIBG based on radiation dose to cell nuclei. (C) Cell survival curves for PARP-targeted radiopharmaceutical therapeutics ( ${ }^{125 I-K X 1},{ }^{131} \mathrm{I}-\mathrm{KX} 1$, and $\left.{ }^{211} \mathrm{At}-\mathrm{MM} 4\right)$ based on radiation dose to cell nuclei.

sites $\left(\mathrm{B}_{\max }\right)(7)$, the correlation between sensitivity to ${ }^{125} \mathrm{I}-\mathrm{KX} 1$ and KX1 (Fig. 3C) reflects the relationship between ${ }^{125} \mathrm{I}-\mathrm{KX} 1$-induced cytotoxicity and its degree of target binding. The weak correlation found between sensitivity to ${ }^{125} \mathrm{I}-\mathrm{KX} 1$ and PARP-1 mRNA should be interpreted with caution, as previous reports demonstrated a lack of correlation between PARP-1 mRNA expression and protein level (14). Although an association is evident between ${ }^{125} \mathrm{I}-\mathrm{KX} 1$ sensitivity and PARP-1 mRNA expression, future studies will be needed to identify the most appropriate method for quantifying PARP-1.

The RBEs of ${ }^{125}$ I obtained from subcellular dosimetry in IMR05 and NLF cell lines were in accordance with the previous understanding of Auger therapy. The RBE of cytoplasmic ${ }^{125}$ I-MIBG was at best equal to $\gamma$-irradiation and was slightly lower, at 0.65 , in IMR-05 cells because of the loss of quadratic $(\beta)$ cell kill at low dose rates (Supplemental Table 3) (10). The RBE of ${ }^{125} \mathrm{I}-\mathrm{KX} 1$, at approximately 2 , demonstrates the high radiotoxicity of Auger therapy but is slightly lower than the previously documented RBE of 4-5 for DNA-incorporated ${ }^{5-125}$ I-iodo-2'-deoxyuridine ( ${ }^{125}$ IdUrd) versus ${ }^{131}$ IdUrd (15). The lower RBE likely results from the distance of $50 \AA$ from the PARP-1 active site to DNA (Supplemental Fig. 2) (16-18), which further increases when PARP-1

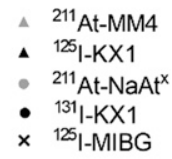

is indirectly bound to DNA via chromatinassociated proteins. Even an angstrom-level increase in distance from DNA leads to a precipitous decrease in the biological effectiveness of ${ }^{125} \mathrm{I}$, where $12 \AA$ is the critical distance (19). Rather, the observed RBE of ${ }^{125} \mathrm{I}-\mathrm{KX} 1$ $(\leq 4)$ against $\gamma$-irradiation matches those of nucleus-targeted Auger emitters noncovalently bound to DNA (20). Therefore, ${ }^{125} \mathrm{I}-\mathrm{KX} 1$ demonstrated a high RBE corresponding to its subcellular targeting, which serves as a key component of its toxicity.

Compared with previously described therapeutic Auger emitters, the major significance of ${ }^{125} \mathrm{I}-\mathrm{KX} 1$ is the combination of high RBE and target specificity. Attempts to specifically deliver Auger emitters with antibodies and small molecules such as ${ }^{125} \mathrm{I}$ MIBG suffered from low cytotoxicity due to nonnuclear localization $(21,22)$. DNAtargeting Auger emitters, including ${ }^{125}$ IdUrd, have demonstrated high effectiveness, but the ubiquitous nature of DNA leads to poor target specificity and high normal-tissue toxicity (23). Although endocrine receptors have been targeted with Auger emitters $(24,25)$, the receptors are not always bound to DNA and a specific endocrine receptor target has not been found in neuroblastoma. A previous study used ${ }^{111}$ In-labeled oligonucleotides complementary to $\mathrm{N}-m y c$ in order to specifically deliver Auger radiation to neuroblastoma (26). Although reduced expression of N-myc led to slowed growth rate, the tumor cells remained viable because of the very limited nuclear uptake of oligonucleotides in unaltered form $(26,27)$.

Interestingly, the increase in RBE with PARP-1 targeting was observed not only with ${ }^{125} \mathrm{I}$ but also with ${ }^{211} \mathrm{At}$, as can be explained by 2 properties specific to ${ }^{211}$ At. First, $\alpha$-emission from ${ }^{211} \mathrm{At}$ is accompanied by recoil of the parent nucleus with a range of $90 \mathrm{~nm}$ in the direction opposite to that which delivers high-LET radiation and therefore contributes to cytotoxicity only when the decay occurs in the nucleus (28). Second, ${ }^{211}$ At also has lesserknown emission of approximately 6.3 Auger electrons per decay, which deposit more radiation dose than $\alpha$-particles within $10 \mathrm{~nm}$ (29). Despite the higher Auger yield of ${ }^{125} \mathrm{I}$, the combined effect of recoil and Auger emission from ${ }^{211}$ At decay makes PARP-1targeted ${ }^{211}$ At therapy a more effective approach.

The benefit of ${ }^{211}$ At-MM4 therapy over ${ }^{125} \mathrm{I}-\mathrm{KX} 1$ was also demonstrated by in vivo tumor dosimetry. Despite ${ }^{125} \mathrm{I}-\mathrm{KX} 1$ 's focused delivery of radiation to the cell nuclei, ${ }^{211}$ At-MM4's much higher nuclear dose per decay and favorable RBE led to 2-ordersof-magnitude-higher therapeutic potency per decay. In the setting of irreversible DNA integration in which the number of ${ }^{125}$ IdUrd decays was 10 -fold higher than that of ${ }^{211}$ AtdUrd, approximately 30 times more tumor dose was deposited by ${ }^{211}$ AtdUrd, congruent with the results of our organ-level dosimetry. The previously established lowest effective therapeutic dose of ${ }^{211} \mathrm{At}-\mathrm{MM} 4$ in IMR-05 tumor-bearing mice was $555 \mathrm{kBq}$ (4), which would 
TABLE 1

In Vitro Dosimetry

\begin{tabular}{|c|c|c|}
\hline Parameter & IMR-05 & NLF \\
\hline \multicolumn{3}{|l|}{ Mean $D_{50} \pm$ SEM (Gy) } \\
\hline${ }^{125} \mathrm{I}-\mathrm{KX} 1$ & $0.18 \pm 0.01$ & $2.0 \pm 0.1$ \\
\hline${ }^{131} \mathrm{I}-\mathrm{KX} 1$ & $0.35 \pm 0.01$ & $3.5 \pm 0.3$ \\
\hline 125I-MIBG & $1.1 \pm 0.1$ & $3.7 \pm 0.3$ \\
\hline${ }^{211} \mathrm{At}-\mathrm{MM} 4$ & $0.051 \pm 0.002$ & $0.56 \pm 0.07$ \\
\hline${ }^{211} \mathrm{At}-\mathrm{NaAt}{ }^{\mathrm{x}}$ & $0.20 \pm 0.01$ & $1.0 \pm 0.1$ \\
\hline External y & $0.71 \pm 0.02$ & $3.7 \pm 0.1$ \\
\hline \multicolumn{3}{|l|}{ RBE for nontargeted therapy } \\
\hline${ }^{125}$ I-MIBG vs. y & 0.65 & 1.0 \\
\hline${ }^{211}$ At-NaAtx vs. y & 3.6 & 3.7 \\
\hline${ }^{211} \mathrm{At}-\mathrm{NaAt}{ }^{\times}$vs. ${ }^{125} \mathrm{I}-\mathrm{MIBG}$ & 5.5 & 3.7 \\
\hline \multicolumn{3}{|l|}{ RBE for targeted therapy } \\
\hline${ }^{125} \mathrm{I}-\mathrm{KX} 1$ vs. ${ }^{131} \mathrm{I}-\mathrm{KX} 1$ & 1.9 & 1.8 \\
\hline${ }^{211}$ At-MM4 vs. ${ }^{131} I-K X 1$ & 6.7 & 6.3 \\
\hline${ }^{211}$ At-MM4 vs. ${ }^{125} \mathrm{I}-\mathrm{KX} 1$ & 3.5 & 3.6 \\
\hline
\end{tabular}

translate to $296 \mathrm{MBq}$ of ${ }^{125} \mathrm{I}-\mathrm{KX} 1$. We predicted that this dose would not be safe in mice, in view of the toxicity of 2 different Auger-emitting therapeutics investigated in previous studies: a ${ }^{125}$ I-labeled monoclonal antibody had a median toxic dose of $111 \mathrm{MBq}$ in mice, and the more cytotoxic DNA-incorporating ${ }^{125}$ IdUrd had a median toxic dose of $74 \mathrm{MBq}$ in rats $(15,30)$. In addition, ${ }^{131} \mathrm{I}$-MIBG has shown antitumor activity in neuroblastoma models at $9.4 \mathrm{MBq}$, which questions the utility of Auger therapy in macroscopic disease (VA Batra, January 6, 2019, unpublished data). Another limitation of ${ }^{125} \mathrm{I}-\mathrm{KX} 1$ is its remarkably long physical half-life of $60 \mathrm{~d}$, compared with the biologic half-life of $1.5 \mathrm{~h}$, as well as its significant target-specific uptake in the spleen and pancreas (7).

Although Auger therapy may be impractical for therapeutic evaluation in solid-tumor models, the present study suggests its potential value in micrometastatic disease. We demonstrated that a PARP-1-targeted Auger emitter has enhanced RBE over $\beta$-emitting analogs at the cellular level. The therapeutic ratio of Auger emitters would be maximized in a micrometastatic setting by providing single-cell lethality without compromising surrounding healthy tissue. Other aspects to improve the translatability of PARP-targeted radiopharmaceuticals for Auger therapy include increasing on-target drug retention at PARP-1 through medicinal chemistry approaches or using shorter-lived Auger emitters such as ${ }^{77} \mathrm{Br}$ to overcome the challenges of using long-lived isotopes.

\section{CONCLUSION}

In this work, we showed that Auger emitters are cytotoxic to high-risk neuroblastoma, with high-LET properties when targeted to PARP-1. However, the utility of systemically administered Auger therapy with unfavorable in vivo kinetics remains questionable for evaluation in solid-tumor models.

\section{DISCLOSURE}

Funding support for the work was received though U.S. Department of Energy grant DE-SC0017646 (Robert Mach) and from the National Institutes of Health through Research Project Grant R01-CA219006 (Daniel Pryma). Robert Mach, Daniel Pryma, and Mehran Makvandi are designated as inventors on a patent held by the University of Pennsylvania that describes the intellectual property associated with ${ }^{211}$ At-MM4 (WO2018218025A1). Daniel Pryma discloses unrelated conflicts, including honoraria and research support from Siemens, Progenics, and 511 Pharma, as well as honoraria from Actinium and Nordic Nanovector. No other potential conflict of interest relevant to this article was reported.

\section{KEY POINTS}

QUESTION: Do Auger emitters exhibit high-LET properties when targeted to PARP-1, and can they be used to treat radiosensitive cancers?

PERTINENT FINDINGS: PARP-1-targeted Auger emitters exhibit high-LET properties, with enhanced RBE in neuroblastoma over $y$ - and $\beta$-radiation but with lower RBE than a-radiation. Dosimetric comparisons between PARP-1-targeted $\alpha$ - and Auger radiation revealed that a-radiation deposits a much higher dose to the tumor than Auger radiation, primarily attributed to the low energy of Auger electrons.

IMPLICATIONS FOR PATIENT CARE: PARP-1 has emerged as a clinical drug target for treating cancers with DNA repair deficiencies, and our studies show that targeting PARP-1 with a- and Auger radiation is potently cytotoxic in neuroblastoma, warranting future clinical translation.
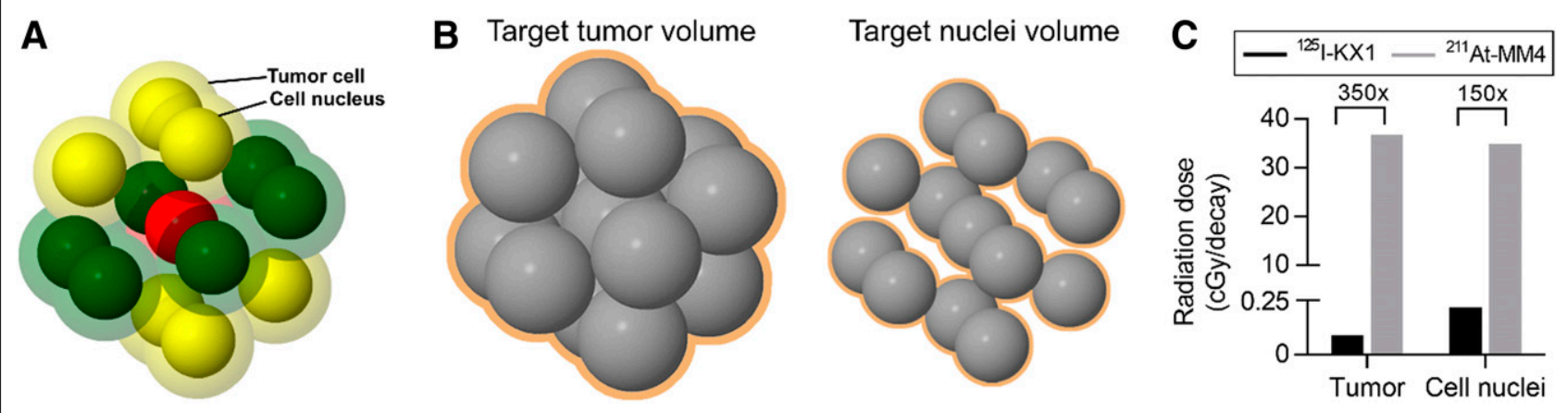

FIGURE 5. In vivo tumor radiation dosimetry with 3-dimensional modeling. (A) Diagram showing tumor cell and its nearest neighbors. Cell (red) receives self-dose as well as cross-dose from neighboring cells on same (green) and different (yellow) planes. (B) Target volume diagrams for conventional organ-level dosimetry (whole tumor) and microdosimetry (cell nuclei). (C) Dose-per-decay-event comparison of ${ }^{211} \mathrm{At}-\mathrm{MM} 4$ and ${ }^{125} \mathrm{I}-\mathrm{KX} 1$. 


\section{REFERENCES}

1. Matthay KK, Maris JM, Schleiermacher G, et al. Neuroblastoma. Nat Rev Dis Primers. 2016;2:16078.

2. Pandit-Taskar N, Modak S. Norepinephrine transporter as a target for imaging and therapy. J Nucl Med. 2017;58(suppl):39S-53S.

3. Carlin S, Akabani G, Zalutsky MR. In vitro cytotoxicity of ${ }^{211}$ At-astatide and ${ }^{131}$ I-iodide to glioma tumor cells expressing the sodium/iodide symporter. $\mathrm{J} \mathrm{Nucl}$ Med. 2003;44:1827-1838.

4. Makvandi M, Lee H, Puentes LN, et al. Targeting PARP-1 with alpha-particles is potently cytotoxic to human neuroblastoma in pre-clinical models. Mol Cancer Ther. 2019;18:1195-1204.

5. Howell RW. Radiation spectra for Auger-electron emitting radionuclides: report no. 2 of AAPM Nuclear Medicine Task Group No. 6. Med Phys. 1992;19:13711383.

6. Koch CJ, Burki HJ. The oxygen-enhancement ratio for reproductive death induced by ${ }^{3} \mathrm{H}$ or ${ }^{125} \mathrm{I}$ damage in mammalian cells. Int J Radiat Biol Relat Stud Phys Chem Med. 1975;28:417-425.

7. Makvandi M, Xu K, Lieberman BP, et al. A radiotracer strategy to quantify PARP-1 expression in vivo provides a biomarker that can enable patient selection for PARP inhibitor therapy. Cancer Res. 2016;76:4516-4524.

8. Batra V, Makvandi M, Zuppa AF, et al. Dexmedetomidine does not interfere with meta-iodobenzylguanidine (MIBG) uptake at clinically relevant concentrations. Pediatr Blood Cancer. 2017;64:e26268.

9. Kamentsky L, Jones TR, Fraser A, et al. Improved structure, function and compatibility for CellProfiler: modular high-throughput image analysis software. Bioinformatics. 2011;27:1179-1180.

10. Kassis AI. Therapeutic radionuclides: biophysical and radiobiologic principles. Semin Nucl Med. 2008;38:358-366.

11. Klutz K, Russ V, Willhauck MJ, et al. Targeted radioiodine therapy of neuroblastoma tumors following systemic nonviral delivery of the sodium iodide symporter gene. Clin Cancer Res. 2009;15:6079-6086.

12. Werner RA, Kobayashi R, Javadi MS, et al. Impact of novel antidepressants on cardiac ${ }^{123}$ I-metaiodobenzylguanidine uptake: experimental studies on SK-N-SH cells and healthy rabbits. J Nucl Med. 2018;59:1099-1103.

13. Vaziri B, Wu H, Dhawan AP, Du P, Howell RW; SNMMI MIRD Committee. MIRD pamphlet no. 25: MIRDcell V2.0 software tool for dosimetric analysis of biologic response of multicellular populations. J Nucl Med. 2014;55:1557-1564.

14. Bieche I, Pennaneach V, Driouch K, et al. Variations in the mRNA expression of poly(ADP-ribose) polymerases, poly(ADP-ribose) glycohydrolase and ADPribosylhydrolase 3 in breast tumors and impact on clinical outcome. Int J Cancer. 2013;133:2791-2800.

15. Kassis AI, Kirichian AM, Wang K, Semnani ES, Adelstein SJ. Therapeutic potential of 5-[ ${ }^{125}$ I] iodo- 2 -deoxyuridine and methotrexate in the treatment of advanced neoplastic meningitis. Int J Radiat Biol. 2004;80:941-946.
16. Langelier MF, Planck JL, Roy S, Pascal JM. Structural basis for DNA damagedependent poly(ADP-ribosyl)ation by human PARP-1. Science. 2012;336:728732.

17. Rose AS, Bradley AR, Valasatava Y, Duarte JM, Prlic A, Rose PW. NGL viewer: web-based molecular graphics for large complexes. Bioinformatics. 2018;34:37553758 .

18. Berman HM, Westbrook J, Feng Z, et al. The Protein Data Bank. Nucleic Acids Res. 2000;28:235-242.

19. Balagurumoorthy P, Xu X, Wang K, Adelstein SJ, Kassis AI. Effect of distance between decaying ${ }^{125} \mathrm{I}$ and DNA on Auger-electron induced double-strand break yield. Int J Radiat Biol. 2012;88:998-1008.

20. Humm JL, Howell RW, Rao DV. Dosimetry of Auger-electron-emitting radionuclides: report no. 3 of AAPM Nuclear Medicine Task Group No. 6. Med Phys. 1994;21:1901-1915.

21. Rutgers M, Buitenhuis CK, van der Valk MA, Hoefnagel CA, Voute PA, Smets LA. $\left[{ }^{131} \mathrm{I}\right]$ and $\left[{ }^{125} \mathrm{I}\right]$ metaiodobenzylguanidine therapy in macroscopic and microscopic tumors: a comparative study in SK-N-SH human neuroblastoma and PC12 rat pheochromocytoma xenografts. Int J Cancer. 2000;90:312-325.

22. Govindan SV, Goldenberg DM, Elsamra SE, et al. Radionuclides linked to a CD74 antibody as therapeutic agents for B-cell lymphoma: comparison of Auger electron emitters with beta-particle emitters. J Nucl Med. 2000;41:20892097.

23. Kassis AI. The amazing world of auger electrons. Int J Radiat Biol. 2004;80:789803.

24. Yasui LS, Hughes A, Desombre ER. Cytotoxicity of ${ }^{125}$ I-oestrogen decay in nonoestrogen receptor-expressing human breast cancer cells, MDA-231 and oestrogen receptor-expressing MCF-7 cells. Int J Radiat Biol. 2001;77:955-962.

25. Kiess AP, Minn I, Chen Y, et al. Auger radiopharmaceutical therapy targeting prostate-specific membrane antigen. J Nucl Med. 2015;56:1401-1407.

26. Watanabe N, Sawai H, Ogihara-Umeda I, et al. Molecular therapy of human neuroblastoma cells using Auger electrons of ${ }^{111}$ In-labeled N-myc antisense oligonucleotides. J Nucl Med. 2006;47:1670-1677.

27. Buchegger F, Perillo-Adamer F, Dupertuis YM, Bischof Delaloye A. Auger radiation targeted into DNA: a therapy perspective. Eur J Nucl Med Mol Imaging. 2006;33:1352-1363.

28. Zalutsky MR, Vaidyanathan G. Astatine-211-labeled radiotherapeutics: an emerging approach to targeted alpha-particle radiotherapy. Curr Pharm Des. 2000;6:14331455 .

29. Unak T. Some microdosmetric data on astatine-211. Appl Radiat Isot. 2003;58: $115-117$.

30. Behr TM, Sgouros G, Vougiokas V, et al. Therapeutic efficacy and dose-limiting toxicity of Auger-electron vs. beta emitters in radioimmunotherapy with internalizing antibodies: evaluation of ${ }^{125} \mathrm{I}-$ vs. ${ }^{131} \mathrm{I}$-labeled CO17-1A in a human colorectal cancer model. Int J Cancer. 1998;76:738-748. 